
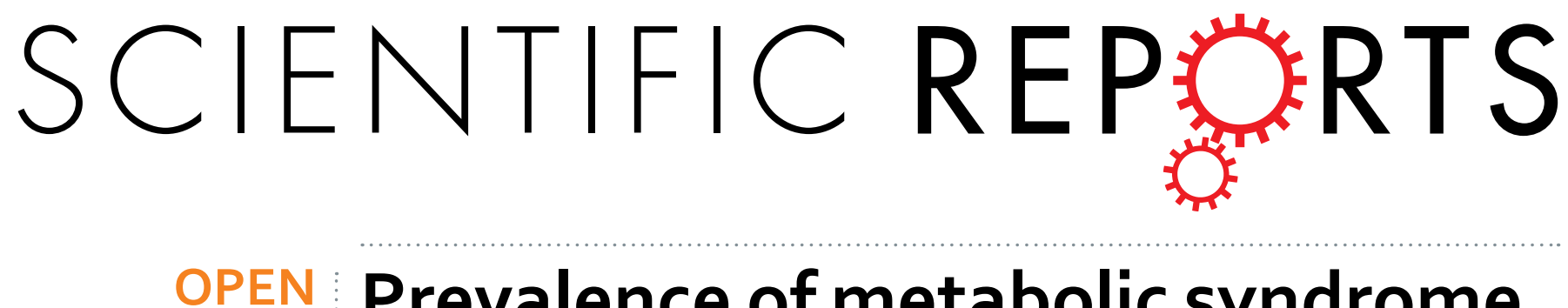

\title{
Prevalence of metabolic syndrome and its risk factors among rural adults in Nantong, China
}

Received: 07 September 2016

Accepted: 03 November 2016

Published: 30 November 2016

\author{
Jing Xiao ${ }^{1, *}$, Chuan-Li Wu ${ }^{1, *}$, Yue-Xia Gao ${ }^{1, *}$, Shu-Lan Wang ${ }^{2}$, Lei Wang ${ }^{2}$, Oing-Yun Lu ${ }^{1}$, \\ Xiao-Jian Wang ${ }^{3}$, Tian-Qi Hua ${ }^{1}$, Huan Shen ${ }^{1}$ \& Hui Cai ${ }^{1,4}$
}

The prevalence of metabolic syndrome (MS) varies worldwide due to genetic and environmental factors. A population-based cross-sectional study, with 37,582 participants recruited in Nantong, China in 2007-2008 (stage I) and 2013 (stage II). Socio-demographic, lifestyle factors, disease history and fasting blood sample were collected. The prevalence of MS was much higher in 2013 (42.6\%) than that in 2007-2008 (21.6\%), which was significantly higher in older people in both stages. Participants with two or more familial history of diseases were associated with a higher MS prevalence compared to those who didn't have familial history of diseases. Total physical activity (PA) was associated with 24 and 19\% decreased risk of MS in men and women. Occupational PA in moderate and vigorous intensity was associated with a $25 \%-45 \%$ decreased risk of MS. Female smokers who smoked more than 10 cigarettes per day or over 25 years were associated with 96 and $74 \%$ increased MS risk, respectively. The highest quartile of rice wine consumption was associated with a lower risk of MS with OR of 0.63 in women, compared with female non-drinkers. These findings indicated that PA and rice wine are two protective factors in MS prevention in rural areas of East China.

Metabolic syndrome (MS), defined as a cluster of metabolic risk factors including central obesity, dysglycemia, reduced high-density lipoprotein cholesterol (HDL-c), elevated triglycerides (TG) and hypertension ${ }^{1}$. It has increased two-fold the risk of cardiovascular disease and five- to nine-fold the risk of type 2 diabetes, compared with those who did not have $\mathrm{MS}^{2,3}$. In addition, MS has a $40 \%$ increased risk of cardiovascular disease mortality ${ }^{4,5}$, and the prevalence of MS has varied around 20-45\% worldwide ${ }^{6,7}$. In China the prevalence has been reported to be $10.6 \%$ and $4.3 \%$ in urban and rural areas in $2002^{8}$. However, MS prevalence in rural China has experienced a dramatic increase, and reached $24.2 \%$ in 2014 because of rapid economic progress and lifestyle transitions in China9.

Lifestyles, behaviors and genetic factors may contribute to the prevalence of MS. Several previous studies found that physical activity (PA), cigarette smoking and alcohol consumption were associated with MS, but the conclusions are inconsistent ${ }^{10,11}$. Furthermore, some recent studies in China have reported the prevalence of MS and related risk factors, including smoking, alcohol consumption, lack of physical activity and familial history of disease, among urban people ${ }^{12,13}$ and rural people ${ }^{2,14}$, respectively. However, the results of these Chinese reports were inconsistent in different provinces and the prevalence varied geographically ${ }^{15}$.

In current study, a two-stage population-based cross-sectional study, 20,502 participants were recruited during 2007-2008 (stage I) and 17,080 participants were recruited in 2013 (stage II). A total of 37,582 participants aged 18-91 years were enrolled in the rural area of Nantong, China. The definition for MS has been proposed by the Joint Interim Statement (JIS) criteria in $2009^{16}$ using an ethnic-specific cut point for waist circumference as the central obesity criterion. The prevalence of MS among rural people in East China was estimated and the associations of smoking status, alcohol consumption, familial history of disease and PA with the prevalence of MS were evaluated. To the best of our knowledge, this is the largest MS study among people in rural China.

${ }^{1}$ Department of Epidemiology and Medical Statistics, School of Public Health, Nantong University, Nantong, Jiangsu, P.R. China. ${ }^{2}$ Rugao Center for Diseases Prevention and Control, Nantong, Jiangsu, P.R. China. ${ }^{3}$ Department of Chronic Disease and Prevention, Center for Disease Control and Prevention of Haian, Nantong, Jiangsu, P.R. China. ${ }^{4}$ Division of Epidemiology, Vanderbilt University Medical Center, 2525 West End Avenue, 6th floor, Nashville, TN, 372031738 , USA. *These authors contributed equally to this work. Correspondence and requests for materials should be addressed to H.C (email: hui.cai@vanderbilt.edu) 


\begin{abstract}
Materials and Methods
Participants. In our study, 43,515 residents aged 18-91 years from four townships in rural Nantong were invited to participate the study by trained interviewers through in-person interview. A total of 37,582 participants were enrolled in our study. Among them 20,502 participants (6,997 men and 13,505 women) were recruited from Liuqiao and Shigang townships between July 2007 and August 2008 with a response rate of 83.6\%, and 17,080 participants (7,805 men and 9,275 women) were recruited from Haian and Rugao townships between March 2013 and November 2013 with the response rate of $89.9 \%$. The details of the data in stage I have been described elsewhere ${ }^{17,18}$. The whole 37,582 participants with a response rate of $86.4 \%$, the reasons for non-participation were refusal $(2.9 \%)$, out of area during enrollment $(7.2 \%)$, and other miscellaneous reasons including poor health or hearing problems (3.5\%). A rural area was defined as an area with a primary administrative unit named a 'village'. Most participants (99.5\%) in our study lived in one of those villages at the time of interview and approximately $59.93 \%(8,871)$ men and $71.14 \%(16,205)$ women were farmers. The Boards of Scientific Research of Nantong University and the Nantong Centers for Disease Control ethics review board approved the ethical protocols and the informed consent was obtained for all participants in this study. And that all experimental protocols were carried out in accordance with approved guidelines.
\end{abstract}

Data collection. Data of socio-demographic characteristics, lifestyle behaviors (including alcohol consumption, smoking status, PA at work and leisure time), personal medical history, and familial history of chronic diseases were collected using the standard questionnaires for all participants. Height, weight and waist circumference were measured and a blood sample was collected for biochemical measurements.

PA. We used a questionnaire similar to the International Physical Activity Questionnaire, an instrument designed primarily for population surveillance activity ${ }^{19}$ with good validity and reliability ${ }^{20}$. We collected the cumulative hours per day spend on light-, moderate- and vigorous-intensity PA in occupational and leisure-time during the latest 7 days of the survey. Intensity levels of both leisure time PA (LPA) and occupational PA (OPA) were classified into four categories: LPA: no LPA (watching TV, reading and writing), light intensity LPA (Qi Gong and some stretching exercises), moderate intensity LPA (jogging and dancing) and vigorous intensity LPA (playing basketball, badminton); OPA: No job or sedentary job (typist, computer operator), light intensity OPA (clerk, teacher), moderate intensity OPA (driver, electrician) and vigorous intensity OPA (farmer, porter). Furthermore, we tertiled the hours per week of moderate- and vigorous-intensity PA in the analysis, respectively: vigorous intensity PA: no, low ( $\leq 19$ hours/week $(\mathrm{h} / \mathrm{w})$ for men and $\leq 28 \mathrm{~h} / \mathrm{w}$ for women) and high $(>19 \mathrm{~h} / \mathrm{w}$ for men and $>28 \mathrm{~h} / \mathrm{w}$ for women); moderate intensity PA: no, low ( $\leq 21 \mathrm{~h} / \mathrm{w}$ for men and $\leq 17.5 \mathrm{~h} / \mathrm{w}$ for women) and high $(>21 \mathrm{~h} / \mathrm{w}$ for men and $>17.5 \mathrm{~h} / \mathrm{w}$ for women). Total PA was calculated by sum of energy expenditure of three PA intensities and presented as metabolic equivalents-hours per week (MET-h/w). MET-h/w values were computed as hours of each PA intensity per week multiplied by its energy requirement: light intensity $=3.3$ METs (based on walking METs), moderate intensity $=4.0 \mathrm{METs}$ and vigorous intensity $=8.0 \mathrm{METs}^{19}$. Total PA in MET-h/w was also classified into three categories based on the tertile categorization and definition as below: total PA: low ( $\leq 110.9$ MET-h/w for men and $\leq 130.0 \mathrm{MET}-\mathrm{h} / \mathrm{w}$ for women), medium $(\leq 245.3 \mathrm{MET}-\mathrm{h} / \mathrm{w}$ for men and $\leq 268.8 \mathrm{MET}-\mathrm{h} / \mathrm{w}$ for women) and high ( $>245.3 \mathrm{MET}-\mathrm{h} / \mathrm{w}$ for men and $>268.8 \mathrm{MET}-\mathrm{h} / \mathrm{w}$ for women).

Smoking, alcohol consumption and socio-demographic factors. Smokers were defined as participants who had smoked at least 100 cigarettes in their lifetime. We collected age of participants who started and stopped smoking and how many cigarettes they consumed per day. Participants were classified into four categories based on quartiles of their smoking intensity by sex: non-smokers, $\leq 10,20$ and $>20$ cigarettes per day for men; non-smokers, $\leq 5, \leq 10$ and $>10$ cigarettes per day for women. Similar categorization was used for the years of smoke. Also we asked participants about their monthly alcohol consumption, including grape wine, rice wine, beer and liquor within a recent year. Among alcohol consumers in our study, only $1.1 \%$ of them consumed grape wine. Thus we only considered the beer, liquor and rice wine consumers in the analysis. One drink was defined as consume approximately 0.5 ounce of absolute alcohol, i.e. 4 .8-ounce of rice wine, 12 -ounce can of beer or 1 ounce of liquor ${ }^{18}$. Based on tertiles of alcohol intake of each type among drinkers, we classified the participants into 4 groups: non-drinkers, light, moderate and heavy drinkers.

Anthropometric and biochemical measurements. All participants were collected anthropometric data and blood sample at in-person interviewed by well-trained interviewers using a standard protocol. Weight, height and waist circumference around the navel were measured twice for each participant to prevent reading and typing errors. A third measurement was taken if difference between two measurements was larger than $1 \mathrm{~cm}$ for height and waist circumference or 1 kilogram $(\mathrm{kg})$ for weight. Then the average of two closely measurements in height, weight, and waist circumference was used in our study. Body mass index (BMI) was calculated using body weight in kilograms divided by the square of body height in meters.

A $10-\mathrm{ml}$ blood sample for each participant, following an overnight fast, was drawn into an EDTA vacutainer tube at in-person interview, which was stored in a portable Styrofoam box with ice packs $\left(0-4^{\circ} \mathrm{C}\right)$ and transported to a laboratory of Nantong Centers for Disease Control or Nantong University within 8 hours. An automated chemistry analyzer (Hitachi 7180, Tokyo, Japan) used to measure glucose and lipid levels within 6-hour serum sample separated by centrifugation of the blood sample. Reagents from the Shino-Test Corporation in Japan were used to enzymatically analyze. The remaining samples were stored at $-70^{\circ} \mathrm{C}$ for additional laboratory assays. The variation coefficient of glucose, HDL-c and TG levels in both inter- and intra- assay were less than 3.5\%.

Other socio-demographic factors, such as age at interview, education (none/elementary school, middle school, high school/college and above), marital status and occupation were treated as potential confounders in our study. 


\begin{tabular}{|c|c|c|c|c|c|c|c|c|c|c|c|c|c|c|}
\hline \multirow[b]{2}{*}{ Age (years) } & \multicolumn{7}{|c|}{ Stage I (6997 men and 13505 women) } & \multicolumn{7}{|c|}{ Stage II ( 7805 men and 9275 women) } \\
\hline & $<30$ & $30-39$ & $40-49$ & $50-59$ & $60-69$ & $\geq 70$ & $\mathbf{p}$ & $<30$ & $30-39$ & $40-49$ & $50-59$ & $60-69$ & $\geq 70$ & $\mathbf{p}$ \\
\hline \multicolumn{15}{|l|}{ Men } \\
\hline MS (n, \%) & $16(5.3)$ & $68(13.8)$ & $197(18.9)$ & $373(17.9)$ & $457(19.4)$ & $112(15.4)$ & $<0.001$ & $84(14.7)$ & $162(22.0)$ & $578(33.3)$ & $731(45.6)$ & $881(51.5)$ & $669(46.3)$ & $<0.001$ \\
\hline Waist $(\mathrm{cm})$ & $78.3 \pm 10.7$ & $83.2 \pm 10.5$ & $84.5 \pm 10.2$ & $83.7 \pm 10.0$ & $82.4 \pm 10.4$ & $80.7 \pm 10.4$ & $<0.001$ & $83.1 \pm 9.5$ & $84.9 \pm 9.1$ & $85.7 \pm 8.5$ & $85.6 \pm 8.5$ & $85.4 \pm 9.1$ & $83.1 \pm 9.3$ & $<0.001$ \\
\hline $\mathrm{TG}(\mathrm{mmol} / \mathrm{L})$ & $1.2 \pm 1.1$ & $1.7 \pm 1.8$ & $1.8 \pm 2.0$ & $1.5 \pm 1.5$ & $1.3 \pm 1.1$ & $1.1 \pm 0.9$ & $<0.001$ & $1.4 \pm 1.2$ & $1.6 \pm 1.3$ & $1.6 \pm 1.2$ & $1.6 \pm 1.2$ & $1.6 \pm 1.1$ & $1.4 \pm 0.9$ & $<0.001$ \\
\hline & +0.4 & $4+0.4$ & $5+0.4$ & $6+0.4$ & $6+0.4$ & $7+04$ & $<0,001$ & $1.3 \pm 0.4$ & $13+04$ & $3+0.4$ & $13+05$ & $1.4 \pm 0.5$ & $1.4 \pm 0.5$ & 0.729 \\
\hline & +05 & 8 & $5+11$ & $5+17$ & 1 & $4+$ & $<0.001$ & 5 & 3 & .3 & 5 & $57-$ & $5.6 \pm 1.4$ & $<0.00$ \\
\hline SBP (mmHg) & 1 & 121.4 & 1 & 124.6 & 1 & 0.1 & $<0.001$ & 9.7 & 123. & 128.0 & $2.7 \pm 15.7$ & 18.6 & 20.4 & $<0$. \\
\hline $\begin{array}{l}\text { DBP } \\
(\mathrm{mmHg})\end{array}$ & 1 & $74.6 \pm 10.3$ & $77.0 \pm 11.2$ & $77.0 \pm 11.0$ & $75.3 \pm 10.8$ & $73.6 \pm 10.8$ & $<0.001$ & $75.4 \pm 7.1$ & $77.5 \pm 7.6$ & $79.7 \pm 9.2$ & $81.7 \pm 10.1$ & $80.8 \pm 10.3$ & $79.0 \pm 10.7$ & $<0$ \\
\hline \multicolumn{15}{|l|}{ Women } \\
\hline MS (n, \%) & $(2.7)$ & $122(8.7)$ & $533(17.4)$ & $1176(27.4)$ & $1116(32.0)$ & $239(30.5)$ & $<0.001$ & $73(10.2)$ & $186(18.4)$ & 798 (35.3) & $946(52.6)$ & $1074(61.5)$ & $1095(62.9)$ & $<0.001$ \\
\hline Waist $(\mathrm{cm})$ & $72.6 \pm 8.2$ & $76.1 \pm 8.7$ & $80.1 \pm 9.7$ & $82.7 \pm 10.0$ & $82.6 \pm 10.7$ & $81.2 \pm 11.4$ & $<0.001$ & $77.1 \pm 8.8$ & $79.3 \pm 8.5$ & $82.5 \pm 8.6$ & $84.6 \pm 9.2$ & $84.2 \pm 9.7$ & $82.4 \pm 9.8$ & $<0.001$ \\
\hline $\mathrm{TG}(\mathrm{mmol} / \mathrm{L})$ & $1.0 \pm 0.7$ & $1.2 \pm 1.1$ & $1.3 \pm 1.2$ & $1.6 \pm 1.3$ & $1.5 \pm 1.2$ & $1.4 \pm 1.0$ & $<0.001$ & $1.2 \pm 0.8$ & $1.4 \pm 0.9$ & $1.5 \pm 1.0$ & $1.7 \pm 1.3$ & $1.7 \pm 1.4$ & $1.6 \pm 1.1$ & $<0.001$ \\
\hline \begin{tabular}{|l|}
$\begin{array}{l}\text { HDL-c } \\
(\mathrm{mmol} / \mathrm{L})\end{array}$ \\
\end{tabular} & \pm 0.3 & $1.5 \pm 0.3$ & $1.5 \pm 0.4$ & $1.6 \pm 0.4$ & $1.6 \pm 0.4$ & $1.6 \pm 0.4$ & $<0.001$ & $1.3 \pm 0.3$ & $1.3 \pm 0.5$ & $1.3 \pm 0.4$ & $1.4 \pm 0.4$ & $1.4 \pm 0.6$ & $1.4 \pm 0.5$ & 0.583 \\
\hline \begin{tabular}{|l|}
$\begin{array}{l}\text { Glucose } \\
(\mathrm{mmol} / \mathrm{L})\end{array}$ \\
\end{tabular} & $4.0 \pm 0.5$ & $4.2 \pm 0.7$ & $4.4 \pm 1.3$ & $4.6 \pm 1.5$ & $4.7 \pm 1.6$ & $4.7 \pm 2.3$ & $<0.001$ & $5.0 \pm 1.0$ & $5.3 \pm 1.3$ & $5.5 \pm 1.5$ & $5.7 \pm 1.7$ & $5.8 \pm 1.6$ & $5.7 \pm 1.5$ & $<0.001$ \\
\hline SBP (mmHg) & $\mid 108.1 \pm 9.8$ & $111.0 \pm 12.6$ & $116.3 \pm 15.8$ & $122.3 \pm 18.4$ & $128.1 \pm 20.1$ & $131.3 \pm 20.3$ & $<0.001$ & $116.8 \pm 10.2$ & $119.8 \pm 12.6$ & $125.5 \pm 14.5$ & $131.8 \pm 17.1$ & $136.8 \pm 19.1$ & $140.6 \pm 20.9$ & $<0.001$ \\
\hline $\begin{array}{l}\text { DBP } \\
(\mathrm{mmHg})\end{array}$ & $68.5 \pm 7.8$ & $70.6 \pm 9.7$ & $73.2 \pm 10.6$ & $74.4 \pm 10.9$ & $74.4 \pm 10.9$ & $73.2 \pm 10.8$ & $<0.001$ & $73.4 \pm 6.8$ & $75.4 \pm 7.8$ & $77.7 \pm 15.9$ & $79.1 \pm 9.9$ & $78.7 \pm 10.0$ & $77.9 \pm 10.4$ & $<0.001$ \\
\hline
\end{tabular}

Table 1. Prevalence of MS and its components in different age groups by two stages $(\bar{X} \pm \mathrm{SD})$.

Criteria of metabolic syndrome. MS was defined based on the most recent Joint Interim Statement (JIS) of the International Diabetes Federation Task Force on Epidemiology and Prevention; National Heart, Lung, and Blood Institute; American Heart Association; World Heart Federation; International Atherosclerosis Society; and International Association for the Study of Obesity ${ }^{16}$ by adopting the Asian criteria for waist circumference. Participants were classified as having MS if they had at least 3 of following metabolic risk factors: central obesity (waist circumference $\geq 85 \mathrm{~cm}$ for Chinese men and $\geq 80 \mathrm{~cm}$ for Chinese women; elevated TG (fasting serum TG $\geq 1.7 \mathrm{mmol} / \mathrm{L}$ or taking medication for abnormal lipid levels); reduced HDL-c (fasting serum $\mathrm{HDL}-\mathrm{c}<1.0 \mathrm{mmol} / \mathrm{L}$ for Chinese men and $<1.3 \mathrm{mmol} / \mathrm{L}$ for Chinese women or specific treatment for this lipid abnormality); elevated blood pressure (SBP $\geq 130 \mathrm{mmHg}$ or $\mathrm{DBP} \geq 85 \mathrm{mmHg}$ or taking hypertension medication); elevated fasting glucose (serum glucose level $\geq 5.6 \mathrm{mmol} / \mathrm{L}$ or taking diabetes medication).

Statistical analysis. Continuous variables were reported as the mean \pm standard deviation (SD) and compared using ANOVA test, and categorical variables were reported as percentages and compared using Pearson chi-square test, between non-MS cases and MS cases in both genders. Odds Ratios (ORs) and 95\% confidence intervals (95\% CIs) were estimated using conditional logistic regression with condition on two stages to assess the associations between MS with PAs, familial history of diseases, smoking status and alcohol consumption. The regression models were adjusted for the potential confounders, including age at interview (continuous), BMI (continuous), marital status, occupation, education level, and mutually adjusted for ever smoker, ever drinker, PA and risk scores of familial history of diseases in our calculation. The test for linear trend was performed by entering the ordinal exposure (such as median of each category in smoking (cigars per day), alcohol consumption and PA) as continuous parameters in the models. The SAS statistical software (version 9.4; SAS Institute, Cary, NC) was used for statistical analyses. All $p$ values presented were based on two-tailed test, and $p<0.05$ was considered statistically significant.

\section{Results}

In current study, the overall prevalence of MS was $42.6 \%$ (45.0\% in female and $39.8 \%$ in male) in 2013, which is much higher than $21.6 \%$ (23.7\% in female and $17.5 \%$ in male) in 2007-2008 in rural Nantong, China. The study also showed that significantly higher prevalence of MS in older people among men and women in each stage in Table 1. The MS prevalence increased from $14.7 \%$ and $10.2 \%$ in age of less than 30 years to $51.5 \%$ and $61.5 \%$ in age of 60-69 years in both men and women in 2013, respectively. However, there were no statistically significant difference of the MS rates between 60-69 years age group and above 70 years age group in women $(\mathrm{p}=0.412)$. Similarly results were found in several MS components (glucose, SBP and DBP). It had the highest glucose level in the age of 60-69 years, the highest SBP in the age above 70 years, and the highest DBP in the age of 50-59 years in both men and women in each stage. The highest waist and TG were found in the age of 40-49 years and 50-59 years in men and women in each stage, respectively. But HDL-c was found significantly increased by age in stage I, and this trend did not occur in stage II.

The selected characteristics between MS cases and non-MS cases in both genders were summarized in Table 2. In brief, the rates of ever smoker between MS cases and non-MS cases were comparable after adjusting for age 


\begin{tabular}{|c|c|c|c|c|c|c|c|c|c|c|c|c|}
\hline & \multicolumn{3}{|c|}{ Men (Stage I) } & \multicolumn{3}{|c|}{ Men (Stage II) } & \multicolumn{3}{|c|}{ Women (Stage I) } & \multicolumn{3}{|c|}{ Women (Stage II) } \\
\hline & Cases & Non-cases & \multirow[b]{2}{*}{$\mathbf{p}$} & Cases & Non-cases & \multirow[b]{2}{*}{$\mathbf{p}$} & Cases & Non-cases & \multirow[b]{2}{*}{$\mathbf{p}$} & Cases & Non-cases & \multirow[b]{2}{*}{$\mathbf{p}$} \\
\hline & $n=1223$ & $\mathrm{n}=\mathbf{5 7 7 4}$ & & $n=3105$ & $\mathrm{n}=4700$ & & $n=3199$ & $n=10306$ & & $n=4172$ & $\mathrm{n}=5103$ & \\
\hline Age (years, $\bar{X} \pm$ SD) & $57.3 \pm 10.6$ & $55.8 \pm 12.7$ & $<0.001$ & $58.6 \pm 13.4$ & $52.2 \pm 16.5$ & $<0.001$ & $57.4 \pm 9.4$ & $51.9 \pm 12.1$ & $<0.001$ & $59.9 \pm 13.7$ & $49.1 \pm 16.4$ & $<0.001$ \\
\hline Height $(\mathrm{cm}, \bar{X} \pm \mathrm{SD})^{1}$ & $167.2 \pm 6.6$ & $165.7 \pm 6.6$ & $<0.001$ & $166.3 \pm 7.0$ & $165.4 \pm 7.1$ & $<0.001$ & $156.3 \pm 5.9$ & $155.6 \pm 6.1$ & $<0.001$ & $155.6 \pm 7.1$ & $155.6 \pm 6.8$ & 0.643 \\
\hline Weight $(\mathrm{kg}, \bar{X} \pm \mathrm{SD})^{1}$ & $74.8 \pm 10.1$ & $62.0 \pm 10.0$ & $<0.001$ & $73.8 \pm 10.8$ & $65.1 \pm 9.7$ & $<0.001$ & $65.5 \pm 9.5$ & $55.9 \pm 9.0$ & $<0.001$ & $64.1 \pm 10.3$ & $58.1 \pm 9.4$ & $<0.001$ \\
\hline $\mathrm{BMI}(\overline{\mathrm{X}} \pm \mathrm{SD})^{1}$ & $26.7 \pm 3.0$ & $22.5 \pm 3.1$ & $<0.001$ & $26.3 \pm 3.3$ & $23.8 \pm 3.0$ & $<0.001$ & $26.8 \pm 3.3$ & $23.0 \pm 3.3$ & $<0.001$ & $26.5 \pm 3.7$ & $24.0 \pm 3.4$ & $<0.001$ \\
\hline \multicolumn{13}{|l|}{ Education $(\%)^{1}$} \\
\hline Primary/under & 40.8 & 54.2 & & 45.2 & 49.2 & & 64.6 & 63.7 & & 65.4 & 60.7 & \\
\hline Middle & 35.7 & 29.5 & & 40.7 & 37.5 & & 25.6 & 26.7 & & 28.9 & 30.7 & \\
\hline High/above & 23.5 & 16.3 & $<0.001$ & 14.1 & 13.3 & $<0.001$ & 9.8 & 9.6 & 0.969 & 5.7 & 8.6 & $<0.001$ \\
\hline \multicolumn{13}{|l|}{ Marital status $(\%)^{1}$} \\
\hline Yes & 92.8 & 89.3 & & 89.0 & 84.9 & & 90.8 & 90.1 & & 85.3 & 83.7 & \\
\hline $\mathrm{No}^{2}$ & 7.2 & 10.8 & 0.002 & 11.0 & 15.2 & $<0.001$ & 9.2 & 9.9 & 0.808 & 14.7 & 16.3 & 0.114 \\
\hline \multicolumn{13}{|l|}{ Farmer $(\%)^{1}$} \\
\hline Yes & 46.1 & 59.3 & & 62.5 & 63.6 & & 69.4 & 69.6 & & 77.3 & 73.8 & \\
\hline No & 53.9 & 40.7 & $<0.001$ & 37.5 & 36.4 & 0.069 & 30.7 & 30.4 & 0.413 & 22.7 & 26.2 & 0.002 \\
\hline \multicolumn{13}{|l|}{ Ever smoker $(\%)^{1}$} \\
\hline Yes & 45.8 & 48.1 & & 49.7 & 48.5 & & 3.6 & 4.0 & & 2.2 & 1.9 & \\
\hline No & 54.1 & 51.9 & 0.125 & 50.3 & 51.5 & 0.348 & 96.4 & 96.0 & 0.168 & 97.8 & 98.1 & 0.399 \\
\hline \multicolumn{13}{|l|}{ Ever drinker $(\%)^{1}$} \\
\hline Yes & 52.6 & 53.9 & & 52.4 & 46.6 & & 9.2 & 12.0 & & 6.4 & 6.2 & \\
\hline No & 47.4 & 46.1 & 0.223 & 47.6 & 53.4 & $<0.001$ & 90.8 & 88.0 & $<0.001$ & 93.6 & 93.8 & 0.741 \\
\hline \multicolumn{13}{|l|}{ Exercise $(\%)^{1}$} \\
\hline Yes & 22.5 & 21.7 & & 18.4 & 13.1 & & 20.4 & 20.4 & & 14.7 & 12.7 & \\
\hline No & 77.5 & 78.3 & 0.615 & 81.6 & 86.9 & $<0.001$ & 79.6 & 79.6 & 0.533 & 85.3 & 87.3 & 0.009 \\
\hline \multicolumn{13}{|l|}{ Diabetes $(\%)^{1}$} \\
\hline Yes & 9.7 & 0.9 & & 8.6 & 1.0 & & 7.4 & 0.6 & & 9.8 & 1.0 & \\
\hline No & 90.3 & 99.1 & $<0.001$ & 91.4 & 99.0 & $<0.001$ & 92.6 & 99.4 & $<0.001$ & 90.2 & 99.0 & $<0.001$ \\
\hline \multicolumn{13}{|l|}{ CVD $(\%)^{1}$} \\
\hline Yes & 2.8 & 1.1 & & 7.6 & 3.2 & & 0.9 & 0.4 & & 6.4 & 3.6 & \\
\hline No & 97.2 & 98.9 & $<0.001$ & 92.4 & 96.8 & $<0.001$ & 99.1 & 99.6 & 0.002 & 93.6 & 96.4 & $<0.001$ \\
\hline
\end{tabular}

Table 2. Characteristics of MS cases and healthy individuals by two stages. ${ }^{1}$ means, percentages, and their $\mathrm{p}$ values were adjusted for age. ${ }^{2}$ Including widowed, divorced/separated and unmarried.

at interview in both genders in each stage. MS cases were older and had higher BMI, and were also more likely to have diabetes and CHD disease than non-MS cases in both genders in each stage. Male MS cases were more educated and had a higher marital rate, and less likely to be farmers, compared with non-MS men in each stage. But in women MS cases were less educated and more likely to be farmers in stage II only. Additionally, MS cases had more exercise in both genders in stage II, Male MS cases were more likely to be alcohol consumers in stage II while female MS cases were less likely to be drinkers in stage I.

Table 3 presents associations of familial history of diseases (including hypertension, diabetes, hyperlipidemia, CHD and stroke in our study) and PAs (including LPA, OPA, hours of vigorous-intensity and moderate-intensity PA of both LPA and OPA) with MS adjusted for potential confounders. Familial history of diseases was associated with increased $20-90 \%$ of MS risk, compared with those people without these diseases in their familial history. Also, increasing risk scores, composed of number of these diseases of familial history, was associated with increased ORs of MS $(\mathrm{p}<0.0001)$ in both genders. There were no association of LPA and the risk of having MS, however moderate to vigorous intensity OPA were associated with a decreased MS prevalence (ORs: 0.74 and 0.54 in men, and 0.69 and 0.73 in women, respectively). For the light intensity OPA, it may decrease $16 \%$ of MS risk in women only, compared with those without OPA or having sedentary work. Furthermore, increasing MET-h/w of total PA was significantly associated with a decreased risk of MS in both men and women, with ORs of 0.76 (95\% CI: 0.71-0.81) for men and 0.81 (95\% CI: 0.76-0.86) for women. Similar results were observed if we used hours/ week $(\mathrm{h} / \mathrm{w})$ for vigorous-intensity or moderate-intensity PA in the analysis. Vigorous-intensity PA ( $>19 \mathrm{~h} / \mathrm{w}$ in men and $>28 \mathrm{~h} / \mathrm{w}$ in women) was associated with 36 and $21 \%$ decreased MS risk, while moderate-intensity PA $(>21 \mathrm{~h} / \mathrm{w}$ in men and $>17.5 \mathrm{~h} / \mathrm{w}$ in women) was associated with equally decreased MS risk of $21 \%$ for men and women, compared with those people without vigorous- or moderate-intensity PA.

Table 4 presents the relationship of MS with cigarette smoking and alcohol consumption. There was no association of cigarette smoking with MS in men after adjustment for multiple confounders. However, we observed that in women current smokers were associated with risk of MS. Women who smoked 10 or more cigarettes per day were associated with $96 \%$ of increased MS risk $(\mathrm{p}=0.0046$ for trend), or who smoked over 25 years were 


\begin{tabular}{|c|c|c|c|c|c|c|c|c|}
\hline & \multicolumn{5}{|c|}{ Men } & \multicolumn{3}{|c|}{ Women } \\
\hline & \multicolumn{2}{|c|}{$\begin{array}{c}\text { Percentages of cases } \\
(\%)\end{array}$} & $\mathrm{OR}(95 \% \mathrm{CI})^{a}$ & OR $(95 \% \mathrm{CI})^{b}$ & & $\begin{array}{c}\text { Percentages of } \\
\text { cases }(\%)\end{array}$ & OR $(95 \% \mathrm{CI})^{a}$ & OR $(95 \% \mathrm{CI})^{b}$ \\
\hline \multicolumn{9}{|c|}{ Familial history } \\
\hline \multicolumn{9}{|l|}{ Hypertension } \\
\hline No & \multicolumn{2}{|c|}{26.50} & 1.0 & 1.0 & & 29.88 & 1.0 & 1.0 \\
\hline Yes & \multicolumn{2}{|c|}{38.08} & $1.67(1.51-1.85)$ & $1.58(1.43-1.75)$ & & 38.46 & $1.57(1.44-1.70)$ & $1.57(1.44-1.70)$ \\
\hline \multicolumn{9}{|c|}{ Hyperlipidemia } \\
\hline No & \multicolumn{2}{|c|}{17.90} & 1.0 & 1.0 & & 22.86 & 1.0 & 1.0 \\
\hline Yes & \multicolumn{2}{|c|}{31.71} & $1.33(0.61-2.90)$ & $1.21(0.55-2.65)$ & & 33.33 & $1.90(1.17-3.08)$ & $1.88(1.15-3.06)$ \\
\hline \multicolumn{9}{|l|}{ Diabeles } \\
\hline No & \multicolumn{2}{|c|}{28.82} & 1.0 & 1.0 & & 31.37 & 1.0 & 1.0 \\
\hline Yes & \multicolumn{2}{|c|}{43.22} & $1.53(1.21-1.93)$ & $1.46(1.15-1.84)$ & & 43.90 & $1.79(1.48-2.18)$ & $1.78(1.46-2.16)$ \\
\hline \multicolumn{9}{|l|}{ CHD } \\
\hline No & \multicolumn{2}{|c|}{28.85} & 1.0 & 1.0 & & 31.51 & 1.0 & 1.0 \\
\hline Yes & \multicolumn{2}{|c|}{36.89} & $1.35(1.12-1.62)$ & $1.31(1.08-1.57)$ & & 37.36 & $1.18(1.00-1.39)$ & $1.18(1.00-1.40)$ \\
\hline \multicolumn{9}{|l|}{ Stroke } \\
\hline No & 28 & & 1.0 & 1.0 & & 30.94 & 1.0 & 1.0 \\
\hline Yes & 45 & & $1.51(1.28-1.77)$ & $1.46(1.24-1.71)$ & & 46.77 & $1.51(1.30-1.75)$ & $1.51(1.30-1.75)$ \\
\hline Risk score & & & & & & & & \\
\hline 0 & 25 & & 1.0 & 1.0 & & 29.22 & 1.0 & 1.0 \\
\hline 1 & 34 & & $1.55(1.40-1.72)$ & $1.49(1.34-1.65)$ & & 36.76 & $1.53(1.41-1.67)$ & $1.53(1.40-1.66)$ \\
\hline$\geq 2$ & 45 & & $1.94(1.66-2.28)$ & $1.82(1.55-2.14)$ & & 44.48 & $1.69(1.47-1.94)$ & $1.69(1.47-1.94)$ \\
\hline $\mathrm{p}$ for trend & & & $<0.0001$ & $<0.0001$ & & & $<0.0001$ & $<0.0001$ \\
\hline Physical acti & & & & & & & & \\
\hline LPA & & & & & & & & \\
\hline No & & 28.24 & 1.0 & 1.0 & & 32.16 & 1.0 & 1.0 \\
\hline Yes & & 28.36 & $0.75(0.66-0.85)$ & $0.88(0.75-1.04)$ & & 27.80 & $0.87(0.79-0.96)$ & $0.90(0.80-1.01)$ \\
\hline LPA (categc & & & & & & & & \\
\hline No & & 28.24 & 1.0 & 1.0 & & 32.16 & 1.0 & 1.0 \\
\hline Light-inter & & 32.02 & $1.47(1.27-1.69)$ & $1.21(1.00-1.46)$ & & 30.29 & $1.19(1.06-1.35)$ & $1.15(0.99-1.34)$ \\
\hline Moderate- & tensity & 20.32 & $1.08(0.85-1.37)$ & $1.03(0.76-1.39)$ & & 23.87 & $1.06(0.91-1.24)$ & $1.05(0.88-1.26)$ \\
\hline Vigorous-i & ensity & 20.78 & $1.02(0.54-1.92)$ & $0.86(0.44-1.71)$ & & 30.14 & $1.30(0.87-1.95)$ & $1.27(0.82-1.95)$ \\
\hline$p$ for trend & & & 0.0011 & 0.3900 & & & 0.0231 & 0.1174 \\
\hline OPA & & & & & & & & \\
\hline No or sede & ary work & 33.76 & 1.0 & 1.0 & & 34.06 & 1.0 & 1.0 \\
\hline Light-inter & & 33.22 & $0.94(0.82-1.08)$ & $0.91(0.79-1.05)$ & & 23.70 & $0.85(0.72-1.00)$ & $0.84(0.71-1.00)$ \\
\hline Moderate- & tensity & 15.15 & $0.71(0.57-0.89)$ & $0.74(0.59-0.93)$ & & 13.90 & $0.72(0.59-0.88)$ & $0.69(0.56-0.85)$ \\
\hline Vigorous- & tensity & 14.71 & $0.49(0.42-0.57)$ & $0.54(0.46-0.64)$ & & 25.82 & $0.71(0.63-0.80)$ & $0.73(0.64-0.84)$ \\
\hline$p$ for trend & & & $<0.0001$ & $<0.0001$ & & & $<0.0001$ & $<0.0001$ \\
\hline Vigorous-int & sity PA (h/v & & & & & & & \\
\hline 0 & & 34.95 & 1.0 & 1.0 & 0 & 36.48 & 1.0 & 1.0 \\
\hline$\leq 19$ & & 29.08 & $0.91(0.79-1.05)$ & $0.93(0.81-1.07)$ & $\leq 28$ & 28.68 & $0.90(0.81-0.99)$ & $0.96(0.86-1.07)$ \\
\hline$>19$ & & 16.87 & $0.63(0.56-0.71)$ & $0.64(0.56-0.72)$ & $>28$ & 23.88 & $0.81(0.73-0.90)$ & $0.79(0.70-0.89)$ \\
\hline$p$ for trend & & & $<0.0001$ & $<0.0001$ & & & 0.0002 & 0.0001 \\
\hline Moderate-int & sity PA & & & & & & & \\
\hline 0 & & 27.28 & 1.0 & 1.0 & 0 & 30.57 & 1.0 & 1.0 \\
\hline$\leq 21$ & & 32.66 & $1.06(0.96-1.18)$ & $1.05(0.95-1.17)$ & $\leq 17.5$ & 36.98 & $1.09(1.00-1.19)$ & $1.10(1.00-1.21)$ \\
\hline$>21$ & & 25.10 & $0.86(0.77-0.95)$ & $0.79(0.70-0.88)$ & $>17.5$ & 28.43 & $0.83(0.76-0.90)$ & $0.79(0.73-0.87)$ \\
\hline$p$ for trend & & & 0.0102 & 0.0001 & & & $<0.0001$ & $<0.0001$ \\
\hline Total PA (MF & $\mathrm{h} / \mathrm{w})$ & & & & & & & \\
\hline$\leq 110.9$ & & 40.61 & 1.0 & 1.0 & $\leq 130.0$ & 45.11 & 1.0 & 1.0 \\
\hline$\leq 245.3$ & & 28.19 & $0.81(0.73-0.90)$ & $0.79(0.70-0.88)$ & $\leq 268.8$ & 25.42 & $0.71(0.65-0.80)$ & $0.71(0.64-0.79)$ \\
\hline$>245.3$ & & 15.81 & $0.55(0.48-0.63)$ & $0.57(0.49-0.66)$ & $>268.8$ & 23.89 & $0.63(0.56-0.71)$ & $0.64(0.56-0.72)$ \\
\hline$p$ for trend & & & $<0.0001$ & $<0.0001$ & & & $<0.0001$ & $<0.0001$ \\
\hline
\end{tabular}

Table 3. Association of familial history of diseases and physical activities with prevalence of MS. ${ }^{\text {a Adjusted }}$ for age at interview and BMI. ${ }^{b}$ Adjusted for age at interview, BMI, education level, marital status, ever smoker and ever drinker, additionally adjusted for occupation and exercise in familial history calculation and adjusted for risk scores of familial history in physical activity calculation, and mutually adjusted for moderate and vigorous PA or LPA and OPA categories. LPA: Leisure-time physical activity. OPA: Occupational physical activity. $p$ for trend was calculated by entering the ordinal exposure as continuous parameters in the model.

associated with $74 \%$ of increased MS risk, compared with women non-smokers. In general, women drinkers, no matter what kind of alcoholic beverage they consumption, were associated with lower risk of having MS with OR of 0.70 (95\% CI: 0.69-0.82). If we combine alcohol intake of beer, liquor and rice wine together, we observed 
that increasing a women's alcohol consumption was associated with $15 \%$ decreased risk of MS ( $p<0.0001$ for the trend). Both number of month and amount of rice wine consumption were inversely associated with MS risk with OR of 0.72 (95\% CI: $0.62-0.82)$ and 0.80 (0.73-0.88), respectively. A similar but weak association pattern was found in months and amount of beer consumption in women. Generally, we didn't find any association of all source of alcohol consumption with MS in men. However, we do find a decreased risk of having MS among rice wine consumers with OR of 0.85 (95\% CI: 0.77-0.95) for months of rice wine consumed and $0.91(0.84-0.98)$ for amount of rice wine consumption in men. Also liquor was not associated with the prevalence of MS in both genders in our study.

Figure 1 depicted the associations between beer, liquor, rice wine and all alcoholic beverage with MS risk in both men and women. We found alcoholic intakes had protective effect on the risk of MS ( $\mathrm{p}=0.0003)$ only in women and this protective effect was strongest at about 10-15 grams alcohol consumed per day and then leveled off when alcohol intake was more than 15 grams per day. The similar protective effect was found in beer and rice wine consumption. In particular, we observed that protective effect of rice wine on MS was gradually increased in both men and women when alcohol consumption was less than 10 grams per day and this effect was stable after 10 grams of rice wine intake.

\section{Discussion}

In our study overall prevalence of MS in 2013 was 42.6\%, which was about 2 times higher than that in 2007. The prevalence was significantly higher in elder people in both genders, and was higher in elder women than in elder man (above 50 years) in both stage I and II. We found that current smokers in women and familial history of hypertension, diabetes, hyperlipidemia, CHD and stroke in both genders were associated with the prevalence of MS, while rice wine consumption and moderate to vigorous intensity OPA were inversely associated with MS risk.

The prevalence of MS in our study was higher than that in previous reports in China: it was $4.9 \%$ to $7.9 \%$ in East China in 2004 to $2005^{21}, 7.3 \%$ in South China in $2002^{8}$, and $7.9 \%$ to $15.1 \%$ in Northwest China in $2010^{2}$. Furthermore we reported the MS prevalence in 2007-2008 was 21.6\% in East China, which was in line with a report of $22.4 \%$ in Northeast China ${ }^{22}$ and in urban Shanghai, East China in $2008^{23}$. However, our data is lower than that in rural Handan of China in 2006-2007 in which the prevalence of MS was $39.7 \%$ and $54.2 \%$ in men and women respectively ${ }^{24}$. The MS prevalence was increased rapidly and it was $42.6 \%$ in East China in 2013, which is comparable with some developed countries or areas, such as rural USA $(39.9 \%)$ and urban USA $(32.8 \%)^{25}$. The high prevalence of MS in our study could be related with high prevalence of obesity, diabetes, dyslipidemia and hypertension due to changes of lifestyles and food intakes in China ${ }^{26,27}$. In consistent with most of these previous studies $^{2,4,25}$, we found that the MS incidence was more common in female (45.0\% and $23.7 \%$ in 2013 and 2007 2008 , respectively) than in male (that is 39.8 and 17.5\%) in rural areas of East China.

We found that familial history of diseases, including hypertension, hyperlipidemia (female only), diabetes, CHD or stroke, was independent risk factor of MS and increased about 20-80\% risk of MS. Among these genetic predisposing factors that affect the prevalence of MS, Paek et al. found that familial histories of hypertension and stroke were risk factors for both men and women, but diabetes and cardiovascular disease were risk factor only for women ${ }^{28}$. Mattsson et al. reported that familial histories of hypertension and diabetes are two determinants of MS in a 21 years follow-up prospective cohort study ${ }^{29}$. The different findings of each study may be related with individual components of $\mathrm{MS}^{30}$, Pei et al. reported that apolipoprotein B is an important marker to segregate individual with MS in Chinese families with familial combined hyperlipidemia ${ }^{31}$. A meta-analysis found that fat mass and obesity related gene FTO plays a critical role in leading to $\mathrm{MS}^{32}$. Also, we found having two or more of those familial histories of diseases increased 82 and 69\% risk of MS in men and women, respectively, compared with those people without any of these diseases of familial histories, which is in line with previous researches, in which they reported that having three or more of these diseases of familial histories or having familial history of dyslipidemia were both associated with MS components ${ }^{33}$. Underline mechanism could be that these different diseases of familial history may share genetic polymorphisms related to MS component level and/or that different genetic polymorphisms related to these different diseases of familial history influence MS component level. However, MS is a complex disorder, the mechanism of genetic variants and interaction between genetic variants and environmental factors still need for further studies.

Previous studies have revealed that PA was associated with lower prevalence of $\mathrm{MS}^{6,17}$. Besides, increasing MET of PA or longer durations of moderate and vigorous PA were associated with a reduced occurrence of $\mathrm{MS}^{34}$. We also found this association in the rural areas of East China. The role of LPA in MS is still inconclusive. One previous study identified that an inverse association between light LPA and MS in overweight adults, and light- or moderate-intensity LPA have higher risk of MS than vigorous-intensity LPA in normal-weight adults $^{35}$. A meta-analysis with 10-years follow-up study reported that a 29 and $32 \%$ lower risk of MS in men and women associated with the highest levels of LPA, but a weaker association between MS and moderate LPA in men, compared with those in the lowest levels of LPA ${ }^{36}$. However, our study was consistent with both Silveira's and Dalacorte's studies ${ }^{37,38}$, in which they did not find any association between LPA and MS in both genders. In our study, we found protective effects of moderate- to vigorous-intensity OPA on MS in both genders and light-intensity OPA could lead to decrease MS risk only in women, compared with people with no or sedentary work. It was consistent with Chu and Mabry's studies that OPA is associated with substantial reduction in the prevalence of $\mathrm{MS}^{39,40}$. However, in Halldin et al.'s study they didn't find any associations between OPA and MS in Stockholm in Sweden ${ }^{41}$. A possible explanation of the association is that in rural areas in China, farmers always have a moderate- or high-intensive OPA, and their energy expenditure mainly derived from OPA, therefore association between MS and OPA could be found. In contrast, in our study only $18.0 \%$ of participants took LPA, most of whom took light intensity LPA, therefore association between MS and LPA is difficult to be found. A possible mechanism of OPA effect on MS could be that PA is known to protect against age-related vascular endothelial dysfunction, and long-term moderate PA may lower systemic oxidative stress. Also, nitric oxide appears to play 


\begin{tabular}{|c|c|c|c|c|c|c|c|}
\hline & \multicolumn{3}{|c|}{ Men } & & \multicolumn{3}{|c|}{ Women } \\
\hline & Percentages of Case (\%) & OR $(95 \% \mathrm{CI})^{a}$ & OR $(95 \% \mathrm{CI})^{b}$ & & Percentages of Case (\%) & OR $(95 \% \mathrm{CI})^{a}$ & OR $(95 \% \mathrm{CI})^{b}$ \\
\hline \multicolumn{8}{|l|}{ Smoking status } \\
\hline Never & 21.89 & 1.0 & 1.0 & & 25.72 & 1.0 & 1.0 \\
\hline Former & 19.23 & $1.00(0.88-1.13)$ & $1.14(0.97-1.35)$ & & 28.80 & $1.06(0.85-1.33)$ & $1.32(1.00-1.73)$ \\
\hline Current & 25.48 & $1.16(0.89-1.52)$ & $1.24(0.89-1.72)$ & & 32.84 & $1.49(0.83-2.67)$ & $2.39(1.22-4.67)$ \\
\hline$p$ for trend & & 0.5284 & 0.0669 & & & 0.2307 & 0.0022 \\
\hline \multicolumn{8}{|c|}{ Smoking rate (cigars per day) } \\
\hline Never & 21.89 & 1.0 & 1.0 & Never & 25.71 & 1.0 & 1.0 \\
\hline$\leq 10$ & 17.04 & $0.87(0.74-1.03)$ & $1.01(0.82-1.24)$ & $\leq 5$ & 27.84 & $1.02(0.71-1.46)$ & $1.21(0.79-1.84)$ \\
\hline$\leq 20$ & 21.37 & $1.12(0.96-1.32)$ & $1.15(0.94-1.41)$ & $\leq 10$ & 29.15 & $1.06(0.75-1.49)$ & $1.34(0.91-2.08)$ \\
\hline$>20$ & 24.73 & $1.04(0.70-1.55)$ & $0.98(0.60-1.62)$ & $>10$ & 35.29 & $1.53(0.95-2.46)$ & $1.96(1.12-3.43)$ \\
\hline$p$ for trend & & 0.3261 & 0.1535 & & & 0.1576 & 0.0046 \\
\hline \multicolumn{8}{|l|}{ Years of smoke } \\
\hline Never & 21.91 & 1.0 & 1.0 & & 25.72 & 1.0 & 1.0 \\
\hline$\leq 25$ & 17.35 & $0.90(0.73-1.11)$ & $1.01(0.79-1.30)$ & & 24.69 & $0.81(0.52-1.21)$ & $0.85(0.53-1.40)$ \\
\hline$>25$ & 20.05 & $1.01(0.88-1.17)$ & $1.11(0.93-1.33)$ & & 31.53 & $1.26(0.96-1.64)$ & $1.74(1.26-2.40)$ \\
\hline$p$ for trend & & 0.8818 & 0.2086 & & & 0.2067 & 0.0028 \\
\hline \multicolumn{8}{|l|}{ Ever drink } \\
\hline Never & 21.61 & 1.0 & 1.0 & & 26.28 & 1.0 & 1.0 \\
\hline Ever & 20.39 & $0.91(0.81-1.03)$ & $0.89(0.76-1.04)$ & & 22.17 & $0.68(0.59-0.78)$ & $0.70(0.69-0.82)$ \\
\hline \multicolumn{8}{|c|}{ Beer: months of drink } \\
\hline 0 & 22.75 & 1.0 & 1.0 & & 26.15 & 1.0 & 1.0 \\
\hline$\leq 3$ & 17.04 & $0.75(0.64-0.87)$ & $0.94(0.79-1.12)$ & & 22.76 & $0.77(0.63-0.93)$ & $0.87(0.70-1.07)$ \\
\hline$>3$ & 17.72 & $0.68(0.55-0.85)$ & $0.73(0.56-0.94)$ & & 19.79 & $0.57(0.41-0.79)$ & $0.61(0.42-0.88)$ \\
\hline$p$ for trend & & $<0.0001$ & 0.0228 & & & $<0.0001$ & 0.0050 \\
\hline \multicolumn{8}{|c|}{ Alcohol from beer $(\mathrm{g} / \mathrm{d})$} \\
\hline 0 & 22.76 & 1.0 & 1.0 & 0 & 26.15 & 1.0 & 1.0 \\
\hline$\leq 6.2$ & 16.47 & $0.67(0.57-0.80)$ & $0.83(0.68-1.01)$ & $\leq 2.8$ & 21.14 & $0.61(0.46-0.82)$ & $0.70(0.51-0.97)$ \\
\hline$\leq 12.3$ & 19.57 & $0.87(0.62-1.23)$ & $1.09(0.74-1.59)$ & $\leq 6.2$ & 22.75 & $0.78(0.62-0.99)$ & $0.88(0.68-1.13)$ \\
\hline$>12.3$ & 17.57 & $0.77(0.63-0.95)$ & $0.88(0.70-1.12)$ & $>6.2$ & 20.98 & $0.70(0.48-1.02)$ & $0.74(0.49-1.13)$ \\
\hline$p$ for trend & & 0.0008 & 0.2737 & & & 0.0005 & 0.0312 \\
\hline \multicolumn{8}{|c|}{ Liquor: months of drink } \\
\hline 0 & 20.03 & 1.0 & 1.0 & & 25.84 & 1.0 & 1.0 \\
\hline$\leq 6$ & 18.00 & $0.88(0.73-1.05)$ & $0.92(0.74-1.14)$ & & 25.83 & $0.85(0.64-1.13)$ & $0.94(0.68-1.30)$ \\
\hline$>6$ & 29.98 & $1.44(1.23-1.70)$ & $1.11(0.87-1.42)$ & & 27.53 & $0.91(0.62-1.31)$ & $0.76(0.47-1.23)$ \\
\hline$p$ for trend & & 0.0009 & 0.6774 & & & 0.2973 & 0.2574 \\
\hline \multicolumn{8}{|c|}{ Alcohol from liquor $(\mathrm{g} / \mathrm{d})$} \\
\hline 0 & 20.13 & 1.0 & 1.0 & 0 & 25.86 & 1.0 & 1.0 \\
\hline$\leq 12.3$ & 19.87 & $0.89(0.60-1.13)$ & $0.85(0.64-1.14)$ & $\leq 6.2$ & 26.46 & $0.88(0.61-1.27)$ & $1.01(0.67-1.54)$ \\
\hline$\leq 37$ & 22.30 & $1.09(0.89-1.32)$ & $1.02(0.80-1.30)$ & $\leq 24.6$ & 22.50 & $0.64(0.40-1.02)$ & $0.67(0.40-1.14)$ \\
\hline$>37$ & 27.68 & $1.35(1.10-1.65)$ & $1.08(0.81-1.43)$ & $>24.6$ & 26.99 & $0.92(0.62-1.36)$ & $0.86(0.53-1.40)$ \\
\hline$p$ for trend & & 0.0099 & 0.7096 & & & 0.1457 & 0.2280 \\
\hline \multicolumn{8}{|c|}{ Rice wine: months of drink } \\
\hline 0 & 23.26 & 1.0 & 1.0 & & 26.27 & 1.0 & 1.0 \\
\hline$\leq 6$ & 16.46 & $0.68(0.58-0.81)$ & $0.85(0.70-1.04)$ & & 21.40 & $0.60(0.48-0.75)$ & $0.68(0.53-0.86)$ \\
\hline$>6$ & 14.34 & $0.59(0.48-0.73)$ & $0.73(0.58-0.93)$ & & 17.72 & $0.55(0.42-0.74)$ & $0.54(0.39-0.75)$ \\
\hline$p$ for trend & & $<0.0001$ & 0.0048 & & & $<0.0001$ & $<0.0001$ \\
\hline \multicolumn{8}{|c|}{ Alcohol from rice wine $(\mathrm{g} / \mathrm{d})$} \\
\hline 0 & 23.26 & 1.0 & 1.0 & 0 & 26.27 & 1.0 & 1.0 \\
\hline$\leq 8.6$ & 15.74 & $0.61(0.49-0.76)$ & $0.80(0.63-1.03)$ & $\leq 4.1$ & 21.54 & $0.61(0.46-0.83)$ & $0.77(0.56-1.05)$ \\
\hline$\leq 25.7$ & 15.34 & $0.67(0.55-0.82)$ & $0.83(0.67-1.04)$ & $\leq 12.8$ & 18.65 & $0.52(0.38-0.71)$ & $0.49(0.35-0.70)$ \\
\hline$>25.7$ & 15.81 & $0.65(0.51-0.84)$ & $0.76(0.57-1.00)$ & $>12.8$ & 19.35 & $0.61(0.45-0.81)$ & $0.63(0.45-0.87)$ \\
\hline$p$ for trend & & $<0.0001$ & 0.0152 & & & $<0.0001$ & $<0.0001$ \\
\hline \multicolumn{8}{|c|}{ All source of alcohol $(\mathrm{g} / \mathrm{d})$} \\
\hline 0 & 21.91 & 1.0 & 1.0 & 0 & 26.31 & 1.0 & 1.0 \\
\hline$\leq 16.4$ & 20.23 & $0.89(0.74-1.05)$ & $0.97(0.79-1.20)$ & $\leq 5.6$ & 22.31 & $0.66(0.52-0.84)$ & $0.73(0.56-0.96)$ \\
\hline$\leq 45.2$ & 18.43 & $0.79(0.67-0.94)$ & $0.78(0.63-0.97)$ & $\leq 18.5$ & 21.06 & $0.64(0.50-0.81)$ & $0.67(0.52-0.87)$ \\
\hline$>45.2$ & 21.54 & $0.97(0.82-1.15)$ & $0.92(0.73-1.16)$ & $>18.5$ & 22.33 & $0.69(0.55-0.88)$ & $0.68(0.51-0.89)$ \\
\hline$p$ for trend & & 0.1619 & 0.1194 & & & $<0.0001$ & $<0.0001$ \\
\hline
\end{tabular}

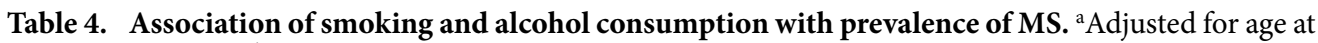
interview and BMI. ${ }^{b}$ Adjusted for age at interview, BMI, education, marital status, occupation, exercise, risk scores of familial history, and mutually adjusted for ever smoker and ever drinker; $p$ for trend was calculated by entering the ordinal exposure as continuous parameters in the model. 
(a)Asscoiation between MS risk and beer intake

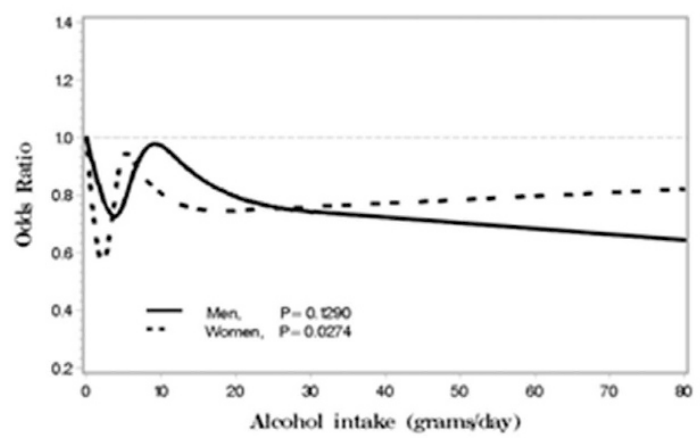

(c)Asscoiation between MS risk and rice wine intake

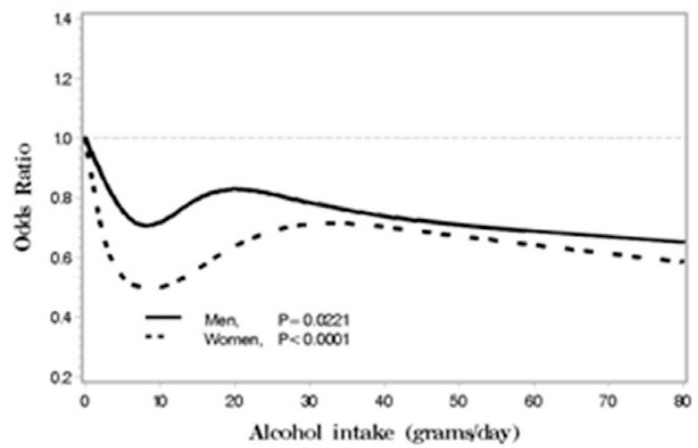

(b)Asscoiation between MS risk and liquor intake

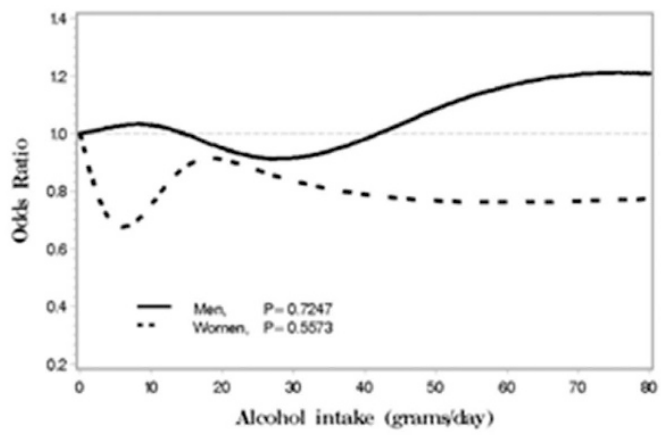

(d)Asscoiation between MS risk and all source of alcohol intake

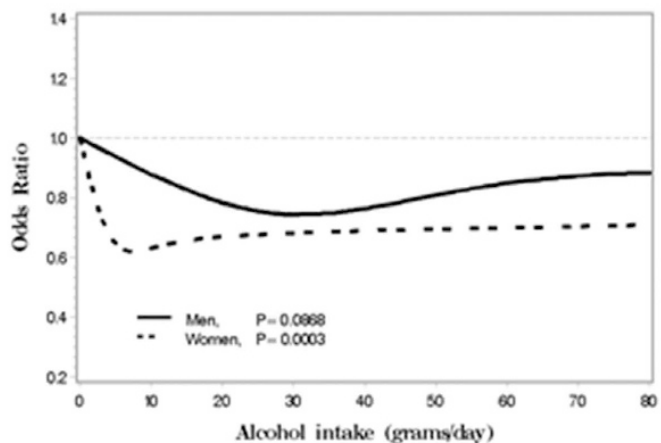

Figure 1. Association between alcohol consumption and MS risk in both men and women. Legend: associations between the MS risk and various alcoholic beverage intakes in 14,802 men and 22,780 women conducted in rural China, and all p values were from liner trend. (a) Beer intake; (b) liquor intake; (c) rice wine intake; (d) all source of alcohol intake.

a role in exercise-induced cardio benefits, such as lowering blood pressure through dilation of blood vessels ${ }^{42}$. In addition, since even non-vigorous activity is associated with higher insulin sensitivity, PA may thereby lower the risk of MS via a similar biological mechanism ${ }^{43}$.

Previous studies have shown conflicting results regarding the influence of smoking on the prevalence of MS. Some studies have reported ever and current smokers were contributed to a higher risk of $\mathrm{MS}^{44,45}$. While no association was found in rural Northwest $\mathrm{China}^{2}$ and in men in urban $\mathrm{China}^{6}$ or even it was a negatively association between smokers and MS risk in rural Northeast China ${ }^{46}$, compared with non-smokers. Most of these studies had small sample sizes and used only univariate analysis without adjustment for possible confounders. Our study had a much larger sample size and adjustment for potential confounders. We found that smoking was an independent risk factor for MS in women, and female smokers who smoked more than 10 cigarettes per day or over 25 years were associated with $96 \%$ or $74 \%$ increased MS risk, compared with non-smokers. Underline mechanics of this association may be related to obesity because a study reported that smoking could increase the risk of abdominal obesity ${ }^{47}$ and insulin resistance ${ }^{48}$.

The influence of alcohol consumption on MS is complicated. A meta-analysis of 6 prospective studies reported that beer or spirits alcohol consumption was associated with an increased risk of MS while wine was associated with a reduced risk of MS in a systematic review ${ }^{49}$ and in $\mathrm{USA}^{50}$. A cohort study in Spain reported that wine or liquor consumption was non-significant association with MS, while beer consumption was associated with higher risk for MS ( $p$ for trend $=0.027$ ) ${ }^{51}$. In our study, we found that total alcohol beverage consumption was associated with decreasing risk of MS under a J-sharped relationship $(p=0.0003$ for trend) only in women. Similar results were found in rice wine, i.e. its consumption associated with decreasing risk of MS in both genders: rice wine consumption of less than 90 grams per day was inversely associated with the prevalence of MS and this protective effect remained if rice wine consumption was more than 90 grams per day. Also, Beer consumption of more than 3 months had a 27 and 39\% decreased risk of MS in men and women. No association was found in liquor consumption. The mechanism of the protective effect could be that the polyphenols enriched in red wine possess multiple benefits on MS through their anti-oxidant, anti-inflammatory, vascular-protective and insulin-sensitizing properties ${ }^{52}$. Resveratrol, a polyphenolic compound enriched in red wine, combating the ageing process induced by nutrient excess ${ }^{53}$. In addition, red wine have higher levels of bioflavonoids, which may induce endothelium-dependent dilation of blood vessels and suppress the synthesis of endothelin-1 (ET-1), a peptide that has a vasoconstricting effect ${ }^{54}$. Chinese rice wine, a widely consumed alcohol by residents in rural 
China, contains large amount of polyphenol and bioflavonoids substance, which may partially explain association of rice wine consumption and low risk of MS.

The strengths of this study include a large sample size in rural East China, and a comprehensive data collected to detect association of MS with PA and alcoholic beverage by different kinds, and extensive information on confounders. However, limitations should take into account. First, the cross-sectional study precludes any casual conclusion and further longitudinal studies should be conducted to confirm the causality relationship. Second, there are 5,586 participants, who had no information of familial history, were excluded from familial history analysis in our study. This exclusion could make a bias in OR estimation. Finally, some of younger males worked out of area during enrollment and cannot be included in this study. It could affect our results, especially in the analysis of younger people.

\section{Conclusions}

This cross-sectional study shows that the prevalence of MS was increasing rapidly from $21.6 \%$ in $2007-2008$ to $42.6 \%$ in 2013, which is both much higher in women than that in men in rural areas of East China. Smoking in women and familial history of hypertension, hyperlipidemia, diabetes, $\mathrm{CHD}$ and stroke aggravated the prevalence of MS. While moderate to vigorous intensity OPA and rice wine consumption in both genders were associated with decreasing the risk of MS. Our findings implicate that OPA and rice wine consumption may possibly contribute to the prevention of MS in rural areas in developing countries, and more preventive efforts should be focused on the individuals with familial history of disease and smokers in rural population.

\section{References}

1. Deepa, M., Farooq, S., Datta, M., Deepa, R. \& Mohan, V. Prevalence of metabolic syndrome using WHO, ATPIII and IDF definitions in Asian Indians: the Chennai Urban Rural Epidemiology Study (CURES-34). Diabetes Metab Res Rev. 23, 127-134 (2007).

2. Zhao, Y. L. et al. Prevalence and Determinants of Metabolic Syndrome among Adults in a Rural Area of Northwest China. PLoS One 9, e91578 (2014).

3. Bhanushali, C. J. et al. Association between Lifestyle Factors and Metabolic Syndrome among African Americans in the United States. J Nutr Metab. 2013, 516475 (2013).

4. Prasad, D. S., Kabir, Z., Dash, A. K. \& Das, B. C. Prevalence and risk factors for metabolic syndrome in Asian Indians: A community study from urban Eastern India. J Cardiovasc Dis Res. 3, 204-211 (2012).

5. Isomaa, B. et al. Cardiovascular morbidity and mortality associated with the metabolic syndrome. Diabetes Care 24, 683-689 (2001).

6. Villegas, R. et al. Prevalence and determinants of metabolic syndrome according to three definitions in middle-aged Chinese men. Metab Syndr Relat Disord. 7, 37-45 (2009).

7. Ramli, A. S. et al. JIS definition identified more Malaysian adults with metabolic syndrome compared to the NCEP-ATP III and IDF criteria. Biomed Res Int. 2013, 760963 (2013).

8. Lao, X. Q. et al. The prevalence of metabolic syndrome and cardiovascular risk factors in adults in southern China. BMC Public Health 12, 64 (2012).

9. Zhou, H. C. et al. Effectiveness of different waist circumference cut-off values in predicting metabolic syndrome prevalence and risk factors in adults in China. Biomed Environ Sci. 27, 325-34 (2014).

10. Yu, M. et al. Associations of cigarette smoking and alcohol consumption with metabolic syndrome in a male Chinese population: a cross-sectional study. Journal of Epidemiology 24, 361-369 (2014).

11. Ekblom, O. et al. Cardiorespiratory fitness, sedentary behaviour and physical activity are independently associated with the metabolic syndrome, results from the SCAPIS pilot study. PLoS One 10, e0131586 (2015).

12. Zhang, T. et al. Metabolic syndrome and its components as predictors of nonalcoholic fatty liver disease in a northern urban Han Chinese population: a prospective cohort study. Atherosclerosis 240, 144-148 (2015).

13. Wang, G. R. et al. Prevalence of metabolic syndrome among urban community residents in China. BMC Public Health 13, 599 (2013).

14. Wang, Y., Xie, B., Tao, Y., Ma, Y. \& Zhang, K. Impact of community-based integrated traditional Chinese and western medicine metabolic syndrome intervention technology in rural residents in southern Jiangsu, China. Med Sci Monit. 21, 2163-2169 (2015).

15. Gu, D. F. et al. Prevalence of the metabolic syndrome and overweight among adults in China. Lancet 365, 1398-1405 (2005).

16. Alberti, K. G. et al. Harmonizing the metabolic syndrome: a joint interim statement of the International Diabetes Federation Task Force on Epidemiology and Prevention; National Heart, Lung, and Blood Institute; American Heart Association; World Heart Federation; International Atherosclerosis Society; and International Association for the Study of Obesity. Circulation 120, 1640-1645 (2009).

17. Cai, H. et al. Prevalence and determinants of metabolic syndrome among women in Chinese rural areas. PLoS One 7, e36936 (2012).

18. Xiao, J. et al. Association of alcohol consumption and components of metabolic syndrome among people in rural China. Nutrition \& Metabolism 12, 5 (2015).

19. Hajian-Tilaki, K. et al. Prevalence of metabolic syndrome and the association with socio-demographic characteristics and physical activity in urban population of Iranian adults: a population-based study. Diabetes Metab Syndr. 8, 170-176 (2014).

20. Bassett, D. R. Jr. International physical activity questionnaire: 12-country reliability and validity. Med Sci Sports Exerc. 35, 1381-1395 (2003).

21. Feng, Y. et al. Prevalence of metabolic syndrome and its relation to body composition in a Chinese rural population. Obesity (Silver Spring) 14, 2089-2098 (2006).

22. Wang, W. et al. Epidemiological investigation of metabolic syndrome and analysis of relevant factors in north-eastern China. J Int Med Res. 38, 150-159 (2010).

23. Xu, W. H. et al. Prevalence of the metabolic syndrome in Pudong New Area of Shanghai using three proposed definitions among Chinese adults. BMC Public Health 10, 246 (2010).

24. Wen, J. P. et al. Comparisons of different metabolic syndrome definitions and associations with coronary heart disease, stroke, and peripheral arterial disease in a rural Chinese population. PLoS One 10, e0126832 (2015).

25. Trivedi, T., Liu, J. H., Probst, J. C. \& Martin, A. B. The metabolic syndrome: are rural residents at increased risk? Journal of Rural Health 29, 188-197 (2013).

26. Wang, X. et al. Prevalence of the metabolic syndrome among employees in northeast China. Chin Med J (Engl). 128, 1989-1993 (2015).

27. Yusuf, S., Reddy, S., Ounpuu, S. \& Anand, S. Global burden of cardiovascular diseases: part I: general considerations, the epidemiologic transition, risk factors, and impact of urbanization. Circulation 104, 2746-2753 (2001).

28. Paek, K. W., Chun, K. H. \& Lee, K. W. Relationship between metabolic syndrome and familial history of hypertension/stroke, diabetes and cardiovascular disease. Journal of Korean Medical Science 21, 701-708 (2006). 
29. Mattsson, N., Ronnemma, T., Juonala, M., Viikari, J. S. \& Raitakari, O. T. Childhood predictors of the metabolic syndrome in adulthood. The Cardiovascular Risk in Young Finns Study. Annals of Medicine 40, 542-552 (2008).

30. Reilly, M. P. \& Rader, D. J. The metabolic syndrome - more than the sum of its parts? Circulation 108, 1546-1551 (2003).

31. Pei, W. D. et al. Apolipoprotein B is associated with metabolic syndrome in Chinese families with familial combined hyperlipidemia, familial hypertriglyceridemia and familial hypercholesterolemia. International Journal of Cardiology 116, 194-200 (2007).

32. Wang, H. N., Dong, S. Q., Xu, H., Qian, J. \& Yang, J. Genetic variants in FTO associated with metabolic syndrome: a meta- and genebased analysis. Molecular Biology Reports 39, 5691-5698 (2012).

33. Suarez-Ortegon, M. F. et al. Association of self-reported familial history of cardiometabolic disease with metabolic syndrome in apparently healthy urban Colombian men. Am J Hum Biol. 25, 228-230 (2013).

34. Esteghamati, A. et al. Association between physical activity and metabolic syndrome in Iranian adults: national surveillance of risk factors of noncommunicable diseases (SuRFNCD-2007). Metabolism-Clinical and Experimental 58, 1347-1355 (2009).

35. Faam, B. et al. Leisure-time physical activity and its association with metabolic risk factors in Iranian adults: Tehran Lipid and Glucose Study, 2005-2008. Prev Chronic Dis. 10, E36 (2013).

36. He, D. et al. Association between leisure time physical activity and metabolic syndrome: a meta-analysis of prospective cohort studies. Endocrine 46, 231-240 (2014).

37. Silveira, V. M., Horta, B. L., Gigante, D. P. \& Azevedo Junior, M. R. Metabolic syndrome in the 1982 Pelotas cohort: effect of contemporary lifestyle and socioeconomic status. Arq Bras Endocrinol Metabol. 54, 390-397 (2010).

38. Dalacorte, R. R., Reichert, C. L. \& Vieira, J. L. Metabolic syndrome and physical activity in southern Brazilian community-dwelling elders: a population-based, cross-sectional study. BMC Public Health 9, 25 (2009).

39. Chu, A. H. \& Moy, F. M. Associations of occupational, transportation, household and leisure-time physical activity patterns with metabolic risk factors among middle-aged adults in a middle-income country. Prev Med. 57, S14-17 (2013).

40. Mabry, R. M., Winkler, E. A. H., Reeves, M. M., Eakin, E. G. \& Owen, N. Associations of physical activity and sitting time with the metabolic syndrome among Omani adults. Obesity 20, 2290-2295 (2012).

41. Halldin, M., Rosell, M., de Faire, U. \& Hellénius, M. L. The metabolic syndrome: prevalence and association to leisure-time and work-related physical activity in 60-year-old men and women. Nutrition Metabolism and Cardiovascular Diseases 17, 349-357 (2007).

42. Taddei, S. et al. Physical activity prevents age-related impairment in nitric oxide availability in elderly athletes. Circulation 101, 2896-2901 (2000).

43. Mayer-Davis, E. J. et al. Intensity and amount of physicial activity in relation to insulin sensitivity: the insulin resistance atherosclerosis study. Journal of the American Medical Association 279, 669-674 (1998).

44. Lin, K. M. et al. Modifiable lifestyle behaviors are associated with metabolic syndrome in a Taiwanese population. J Nurs Scholarsh. 47, 487-495 (2015)

45. Amarasinghe, S., Balakumar, S. \& Arasaratnam, V. Prevalence and factors associated with metabolic syndrome among Tamils aged over 18 years in Jaffna district, Sri Lanka. J Diabetes Metab Disord. 14, 61 (2015).

46. Yu, S., Guo, X., Yang, H., Zheng, L. \& Sun, Y. An update on the prevalence of metabolic syndrome and its associated factors in rural northeast China. BMC Public Health 14, 877 (2014).

47. Oh, S. W. et al. Association between cigarette smoking and metabolic syndrome - The Korea National Health and Nutrition Examination Survey. Diabetes Care 28, 2064-2066 (2005).

48. Chiolero, A., Faeh, D., Paccaud, F. \& Cornuz, J. Consequences of smoking for body weight, body fat distribution, and insulin resistance. American Journal of Clinical Nutrition 87, 801-809 (2008).

49. Sun, K. et al. Alcohol consumption and risk of metabolic syndrome: A meta-analysis of prospective studies. Clinical Nutrition 33, 596-602 (2014)

50. Djousse, L. et al. Alcohol consumption and metabolic syndrome: Does the type of beverage matter? Obesity Research 12, 1375-1385 (2004).

51. Barrio-Lopez, M. T. et al. Different types of alcoholic beverages and incidence of metabolic syndrome and its components in a Mediterranean cohort. Clin Nutr. 32, 797-804 (2013).

52. Shi, L. et al. Physical activity, smoking, and alcohol consumption in association with incidence of type 2 diabetes among middleaged and elderly Chinese men. PLoS One 8, e77919 (2013).

53. Baur, J. A. \& Sinclair, D. A. Therapeutic potential of resveratrol: the in vivo evidence. Nat Rev Drug Discov. 5, 493-506 (2006).

54. Corder, R. et al. Oenology: red wine procyanidins and vascular health. Nature 444, 566 (2006).

\section{Acknowledgements}

We deeply appreciate the participants of the Nantong Metabolic Syndrome Study in Nantong, China. This work was supported by the National Natural Science Foundation of China $(31000539,81502827)$, the Ministry of Science and Technology of China (2006 BA 101A01), and the Department of Science and Technology of Nantong (BK2011059, S2010042). The funders had no role in study design, data collection and analysis, decision to publish or preparation of the manuscript.

\section{Author Contributions}

J.X., C.W., Y.G. and H.C. participated as investigators, in the discussion of the research and contributed to the study design, the data analysis and in writing the manuscript. S.W., L.W., Q.L. and X.W. contributed to enrolled participants, collected data and critically reviewed the manuscript. T.H. participated in the data collected and interpretation of the research. H.S. revised the manuscript. J.X. and H.C. conceived and designed the main study and is the guarantor of this work and, as such, had full access to all the data in the study and take responsibility for the integrity of the data and the accuracy of the data analysis. H.C. revised the article for important intellectual content and approved the final version for submission. All authors read and approval the final manuscript to be published.

\section{Additional Information}

Competing financial interests: The authors declare no competing financial interests.

How to cite this article: Xiao, J. et al. Prevalence of metabolic syndrome and its risk factors among rural adults in Nantong, China. Sci. Rep. 6, 38089; doi: 10.1038/srep38089 (2016).

Publisher's note: Springer Nature remains neutral with regard to jurisdictional claims in published maps and institutional affiliations. 
(c) (i) This work is licensed under a Creative Commons Attribution 4.0 International License. The images or other third party material in this article are included in the article's Creative Commons license, unless indicated otherwise in the credit line; if the material is not included under the Creative Commons license, users will need to obtain permission from the license holder to reproduce the material. To view a copy of this license, visit http://creativecommons.org/licenses/by/4.0/

(C) The Author(s) 2016 